\title{
Assessment of Climate Changing Effect on Precipitation and Temperature of Tehran
}

\author{
Nadia Keshmiri* \\ Graduated from University of Tehran, University of Tehran, Faculty of Geography, Department of Physical \\ Geography \\ *Corresponding Author Email: Nadia.keshmiri@gmail.com
}

\begin{abstract}
In this study, we have studied the effect of climate change on precipitation and temperature in Tehran. Climate change affects many aspects of human activity and this effect is greater in large cities such as Tehran so this is an important issue and the main purpose of this study is to investigate the possible changes in the two main parameters related to climate elements (temperature and precipitation). For the coming years, the Tehran city is based on the past climate of this city. To investigate the effect of climate change on precipitation and temperature in Tehran, 30 year statistics and information of 2 stations (Mehrabad and Doshan Tape) in relation to the parameters of precipitation, maximum temperature and minimum temperature based on the daily scale were received from the Meteorological Organization. After the initial statistical corrections on the data based on the Mann-Kendall method for the period 1982 to 2012, we examined the significant trend of the data (incremental and decremental). Then we used the SDSM model to predict the situation from 2015 to 2045 . The results of this study showed that based on the effects of climate change in Tehran for Mehrabad and Doshan Tappeh stations, the city will face a decrease in precipitation in the future. Also the minimum and maximum temperatures in Tehran (which has increased significantly since 2000) will increase by 2045 . This shows the trend of increasing the minimum and maximum temperatures until 2045.
\end{abstract}

Keywords: climate change, precipitation, temperature, Tehran

\section{INTRODUCTION}

Atmospheric science is a branch of earth science that studies the planet earth's atmosphere. The most important of these sciences is meteorology. The main factor separating the two sciences is related to time scale. It is clear that the weather is always changing, but usually in a certain area, a certain weather is more reproducible during the year so the climate refers to the prevailing weather in a place for a long period of time (Kaviani and Alijani, 2012). Earth's climate can be divided into 5 elements: atmosphere hydrosphere cryosphere lithosphere and biosphere. Earth's climate is based on the Earth's internal processes. (Meshkatee, 2015).

As mentioned earlier, the climate reflects the general weather condition of an area and its changes are not severe and continuous. Of course this is true for short-term trends, but in long-term trends this is usually not the case and we see a lot of changes. In fact climate is a factor that both causes change and is influenced by factors. Weather has undergone fundamental changes over the last millions of years. Climate change is emerging in the form of short-term and long-term changes. The effects of these changes are evident in nature and prove the existence of these climatic changes (Kaviani and Alijani, 2001). "Transformation" is one of the characteristics of climate and perhaps its most fundamental principle. Within these climatic changes, we see many fluctuations and ups and downs (Asakereh, 2007). 
The issue of climate change which is one of the most common scientific and even socio-political issues in the present era, is not a new issue. In fact, change and motion are an intrinsic part of the atmospheric system (Azizi, 2004). The most important effects of climate change are its effect on atmospheric and climatic phenomena such as storms, floods, hail, drought, heat waves and early cold. In this case, it is expected that limit phenomena will have an increasing trend over the coming decades (Babaeian et al., 2010).

Air inversion phenomenon is one of the problems of air pollution in Tehran, especially in cold seasons. The time of air pollution starts from 6:30 a.m. During these hours, most of the air pollution in Tehran is related to the market. Infected streams move east in the afternoon. The best weather in Tehran is in the northwestern part. Another issue related to air pollution in Tehran is the sharp decrease in the field of view. In more than 200 days of the year, the concentration of airborne particles in Tehran is somewhat high. The field of view reaches less than 500 meters so residents of two-thirds of the south of the city often see only a blurry image of Mount Tochal. Residents of the northern third of the city can hardly see the southern two-thirds and most of this part of the city is seen in a halo of gray smoke.

Chie Kavo and Gangoli (2011) studied the intensity, continuity and frequency of limited precipitation in relation to 20th century global warming scenarios. They found that the trend of marginal precipitation is expanding rapidly on a global scale and has obvious effects on intensity curves, continuity and frequency. Niuw et al. (2006) also examined the evidence for this trend at daily climatic limits in southern and western Africa based on climatic data from 14 African countries. The results of this study show that the number of cold days and nights in this area has a decreasing trend and the number of hot days and nights has an increasing trend. There is also more heavy precipitation in this area. Brown et al. (2010) in their study entitled "Climatic Indicators in the Northeast of America for the period 1870 to 2005", calculated the temperature and precipitation limit indices for 40 stations. According to their calculations, temperature indices are increasing in relation to the frequency of hot events, the frequency of cold events is decreasing and the precipitation is often more humid. Isnaf et al. (2012) examined the trend of precipitation and temperature-related climate events for New York City. They found that the number of icy days per year was decreasing and the amount of heavy precipitation was increasing.

Climate change is one of the major threats to sustainable development in areas such as the environment, human health, food security, economic activity, natural resources and infrastructure so conduct related research to be better prepared to deal with and reduce damage. This is a very important issue. Also most environmental projects today focus on recognizing climate change and mitigating its effects. Implementation of development, economic and social plans also requires knowledge of climate change for proper planning so it is necessary to conduct climate studies for planning at the national, provincial and urban levels.

\section{RESEARCH METHODS}

In this study, to investigate the effect of climate change on precipitation and temperature changes in Tehran, we collected statistics and information from Mehrabad and Doshan Tappeh stations regarding precipitation, maximum temperature and minimum temperature on a daily basis from the Meteorological Organization. After the initial statistical corrections on the data based on the Mann-Kendall method for the period 1982 to 2012, we examined the significant upward and downward trend of this data. Finally, we used the SDSM model to predict the situation between 2015 and 2045.

\section{SDSM micro-scale statistical exponential model}

Robert L. Weibley and Christian W. Dawson, with the support of the Climate Impact Assessment Consortium, developed the Climate Impact Scenarios Project in Canada and the UK and Wales Environment Agency. This model can make statistical connections between large-scale behaviors (they predict) and localscale behaviors (they are predicted) based on multiple linear regression method. These connections are made using station data and the output of public circulation models over a similar period. Here it is assumed that these relationships exist in the same way for the future. In other words, the fundamental assumption in the micro-scale statistical exponential is the temporal independence of these relationships. Before performing the exponential micro-scale process by this model, the observational data and the data related to the general circulation models are normalized based on the mean values and the standard deviation in the desired period (Meshkatee, 2015).

The Mann-Kendall method was first proposed by Mann (1945). This method was then developed by Kendall (1970). Hypothesis 0 of the Mann-Kendall test indicates that the data series is random and no trend can be observed in them and acceptance of Hypothesis 1 (to reject Hypothesis 0) also indicates the existence of a trend in the data series. In this method, first the difference between each observation and all subsequent observations is calculated and then the parameter $\mathrm{S}$ is calculated based on the following formula: 


$$
S=\sum_{k=1}^{n-1} \sum_{j=k+1}^{n} \operatorname{sgn}\left(x_{j}-x_{k}\right)
$$

In the above formula, $n$ represents the number of observations in the series and $x_{j}$ and $x_{k}$ represent the $j$-th and $\mathrm{k}$-th data of this series, respectively. The function of the sgn symbol is also calculated as follows:

$$
\begin{gathered}
\text { (2) for }\left(\mathrm{x}_{\left.\mathrm{j}-\mathrm{x}_{\mathrm{k}}\right)>0} \operatorname{sgn}\left(x_{j}-x_{k}\right)=+1\right. \\
\text { for }\left(\mathrm{x}_{\mathrm{j}}-\mathrm{x}_{\mathrm{k}}\right)=0 \\
\operatorname{sgn}\left(x_{j}-x_{k}\right)=0 \\
\text { for }\left(\mathrm{x}_{\left.\mathrm{j}-\mathrm{x}_{\mathrm{k}}\right)<0} \operatorname{sgn}\left(x_{j}-x_{k}\right)=-1\right.
\end{gathered}
$$

In the next step, the calculation of variance $S$ is calculated using one of the following two equations:

$$
\begin{gathered}
\operatorname{Var}(S)=\frac{n(n-1)(2 n+5)-\sum_{i=1}^{m} t(t-1)(2 t+5)}{18} \\
\text { (4) for } \mathrm{n}<10 \\
\operatorname{Var}(S)=\frac{n(n-1)(2 n+5)}{18}
\end{gathered}
$$

In the above formulas, $\mathrm{n}$ and $\mathrm{m}$ represent the number of sequences that have at least one iterative data. The variable $t$ indicates the frequency of data that has the same value in a sequence (number of nodes). Finally, the $\mathrm{Z}$ statistic is calculated using one of the following two equations:

$$
\begin{array}{rl} 
& z=\frac{S-1}{\sqrt{\operatorname{Var}(S)}} \\
(5) \text { for } \mathrm{S}>0 & \\
\text { for } \mathrm{S}=0 & z=0 \\
z & =\frac{S+1}{\sqrt{\operatorname{Var}(S)}}
\end{array}
$$

Here based on the assumption of two trend test domains, Hypothesis 0 is accepted when the following condition is true:

$$
|Z|<Z_{\alpha / 2}
$$

In the above equation, $\alpha$ represents the meaningful level that is considered for the test. $Z \alpha$ represents the standard normal distribution statistic at the meaningful level for $\alpha$ and given that the test has two domains so $\alpha / 2$ has been used. In this study, this test is considered for 95 percent and 99 percent confidence levels. Here if $Z$ is a positive number, then the trend of the data series will be upward and if $Z$ is a negative number, then the trend of the data series will be downward (Mann 1945, Kendall 1970).

The Tehran city is located in an area between mountains and deserts on the southern slopes of the Alborz. Also the Tehran city has developed from the south and southwest to the flat plains of Shahriyar and Varamin. The Tehran city also reaches a mountain in the north and east. The natural area of Tehran's geographical space includes mountains and plains and is determined by the Jajroud and Karaj rivers. These rivers divide the central Alborz Mountain in the northern wall of Tehran into 3 independent parts. The climatic situation of Tehran is strongly influenced by three factors: mountains, deserts and humid westerly winds. The desert factor and the west wind factor have a greater effect on the weather in Tehran. The Alborz Mountains also moderate the climate of the foothills and valleys. The penetration of westerly winds in the Tehran city and mountain streams in the plains is not enough to neutralize the negative role of the desert in the weather of Tehran. In summer, desert winds blow from the southeast and from Masile area to the Tehran city and the mountainous atmosphere of Tehran is such that the whole city is affected by dust. These winds are dry and sometimes cause sandstorms and this is a prominent feature of desert winds. 
The moderating role of Alborz Mountain for the climate of skirt areas is proved by observing the temperature and precipitation in 3 areas of Shemiran, Tehran and Rey based on topographic conditions and altitude. In Shemiran, we see a milder weather with more precipitation, but other areas of Tehran have warmer weather with less precipitation (Saeidniya, 1989).

\begin{tabular}{cccc}
\hline & Shemiran & Tehran city & Rey \\
\hline $\begin{array}{c}\text { Average annual temperature } \\
\text { in Celsius }\end{array}$ & $23 \mathrm{C}^{\circ}$ & $29 \mathrm{C}^{\circ}$ & $30 \mathrm{C}^{\circ}$ \\
\hline $\begin{array}{c}\text { Maximum annual } \\
\text { temperature in Celsius }\end{array}$ & $36 \mathrm{C}^{\circ}$ & $42 \mathrm{C}^{\circ}$ & $43 \mathrm{C}^{\circ}$ \\
\hline $\begin{array}{c}\text { Minimum annual } \\
\text { temperature in Celsius }\end{array}$ & $-17 \mathrm{C}^{\circ}$ & $-6 \mathrm{C}^{\circ}$ & $-5 \mathrm{C}^{\circ}$ \\
\hline $\begin{array}{c}\text { Annual precipitation in } \\
\text { Millimeter }\end{array}$ & $104 \mathrm{~mm}$ & $43 \mathrm{~mm}$ & $42 \mathrm{~mm}$ \\
\hline
\end{tabular}

\section{Study stations}

\begin{tabular}{|c|c|c|c|}
\hline Station name & Longitude & Latitude & Period \\
\hline Mehrabad & $19.51^{\circ}$ & $35.41^{\circ}$ & 1982 to 2012 \\
\hline Doshan Tappeh & $51.20^{\circ}$ & $35.42^{\circ}$ & 1982 to 2012 \\
\hline
\end{tabular}

\section{Mann-Kendall graphic test results}

\section{Mehrabad Station}

\section{Minimum temperature}

In Figure 4-1 you can see that the elements U (black graph) and U' (red graph) for the minimum temperature parameter are out of the critical range ( \pm 1.96$)$. According to the Mann-Kendall method (described earlier in the Materials and Methods chapter), if these two components go beyond the critical range, then this indicates a trend in time series. The direction of the trend is also determined based on the direction of the $U$ component, where $+\mathrm{U}$ indicates a positive trend in the data and $-\mathrm{U}$ indicates a negative trend in the data. Also in examining the minimum 30 year temperature of Mehrabad station (1983 to 2012) based on Mann-Kendall method, we can conclude that this parameter in Mehrabad station has had a positive trend during this period. On the other hand, the intersection of the two components $U$ and $U$ 'indicates that the time of the beginning of sudden change and jump of the station's minimum temperature is after 1990. In general, the minimum temperature of this station has been increasing in recent years which will intensify after 2000 .

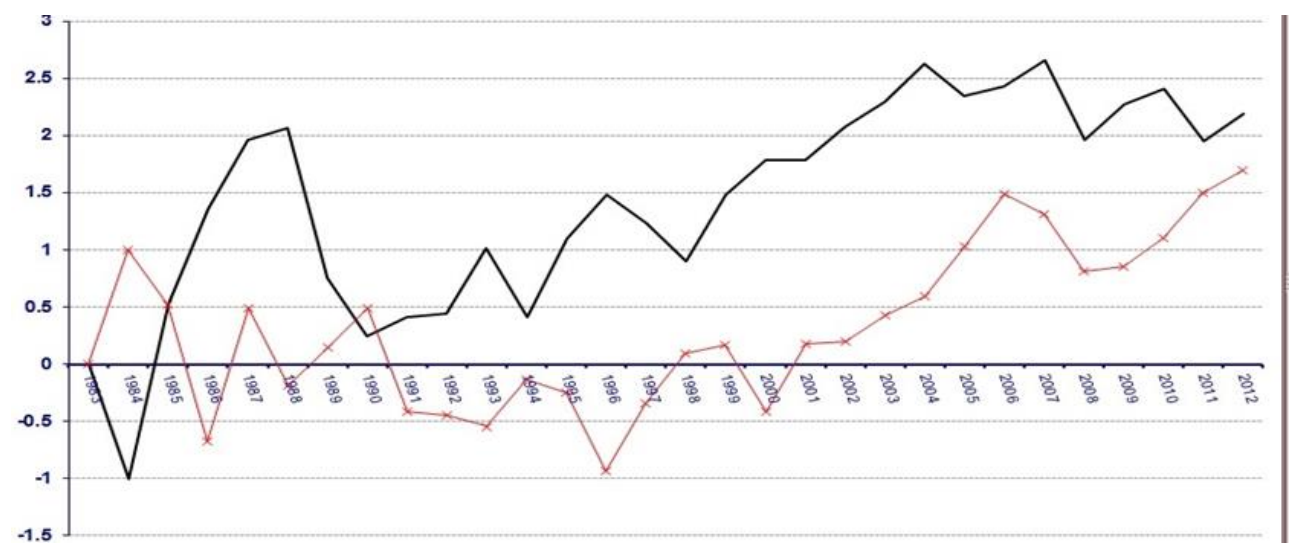

Figure 1. Statistics diagram of $U$ and $U^{\prime}$ for minimum temperature $\left(C^{\circ}\right)$ at Mehrabad station (1983 to 2012)

\section{Maximum temperature}

In Figure 4-2 you can see that the components U (black graph) and U' (red graph) for the maximum temperature parameter are out of the critical range $( \pm 1.96)$. According to the Mann-Kendall method, if these two components go beyond the critical range, this indicates the existence of trends in time series. The direction of the trend is also determined based on the direction of the $\mathrm{U}$ component, where $+\mathrm{U}$ indicates a positive trend in 
the data and $-\mathrm{U}$ indicates a negative trend in the data. Also in examining the maximum 30 year temperature of Mehrabad station (1983 to 2012) based on Mann-Kendall method, we can conclude that this parameter in Mehrabad station has had a positive trend in this time period. On the other hand, the collision of the two components $U$ and $U^{\prime}$ indicates that the time of the beginning of sudden change and jump in the maximum temperature of this station is after 1984. In general, the maximum temperature of this station has been increasing in recent years which will intensify after 2002.

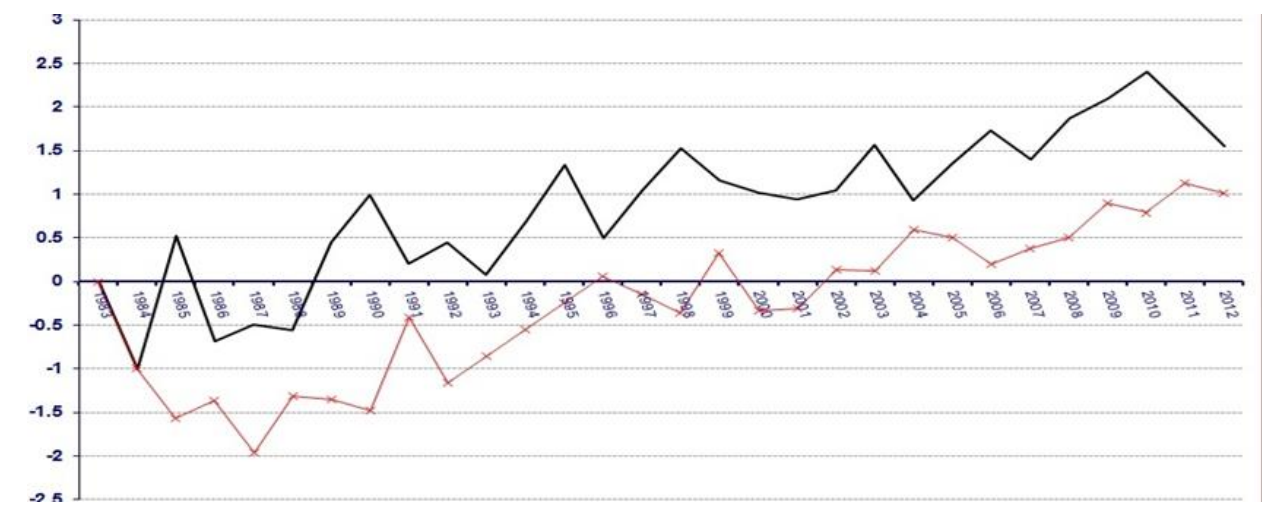

Figure 2. Statistics diagram of $U$ and $U$ 'for maximum temperature $\left(C^{\circ}\right)$ at Mehrabad station (1983 to 2012)

\section{Precipitation}

In Figure 3-4, you can see that the components U (black graph) and U' (red graph) for the precipitation parameter are out of the critical range $( \pm 1.96$ percent). According to the Mann-Kendall method, if these two components go beyond the critical range, this indicates the existence of trends in time series. The direction of the trend is also determined based on the direction of the $U$ component, where $+U$ indicates a positive trend in the data and - $U$ indicates a negative trend in the data. Also in the study of 30 years of precipitation at Mehrabad station (1983 to 2012) based on Mann-Kendall method, we can conclude that this parameter at Mehrabad station had a negative trend during this period. On the other hand, the collision of the two components $U^{\text {and } U^{\prime}}$ indicates that the time of the beginning of sudden change in the precipitation of this station is after 1998 to 2000. In general, the precipitation of this station has been decreasing in recent years which will intensify after 2001.

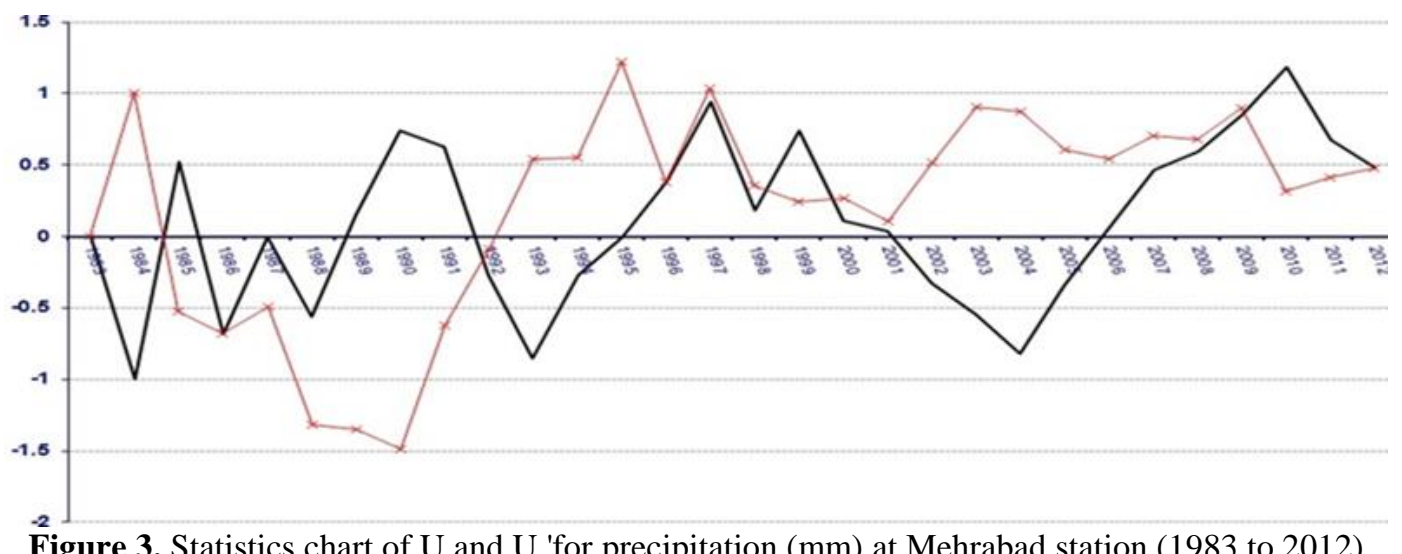

Figure 3. Statistics chart of U and U 'for precipitation (mm) at Mehrabad station (1983 to 2012)

\section{Doshan Tappeh Station}

\section{Minimum temperature}

In Figure 4-4 you can see that the elements U (black graph) and U' (red graph) for the minimum temperature parameter are out of the critical range ( \pm 1.96$)$. According to the Mann-Kendall method (described earlier in the Materials and Methods chapter), if these two components go beyond the critical range, then this indicates a trend in time series. The direction of the trend is also determined based on the direction of the $U$ component, where $+\mathrm{U}$ indicates a positive trend in the data and $-\mathrm{U}$ indicates a negative trend in the data. Also in examining the minimum 30 year temperature of Doshan Tappeh station (1983 to 2012) based on Mann-Kendall method, we can conclude that this parameter in Doshan Tappeh station has had a positive trend during this period. On the other hand, the intersection of the two components $U$ and $U$ ' indicates that the time of the 
beginning of sudden change and jump of the station's minimum temperature is after 1990. In general, the minimum temperature of this station has been increasing in recent years which will intensify after 2000.

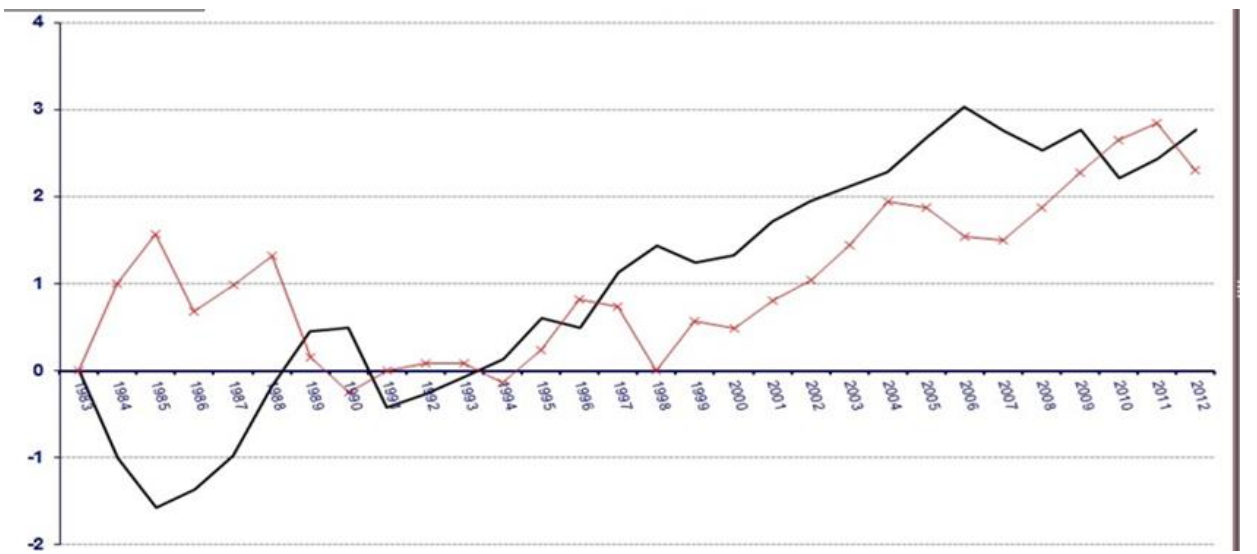

Figure 4. Chart of $U$ and $U$ 'statistics for minimum temperature $\left(C^{\circ}\right)$ at Doshan Tappeh station (1983 to 2012)

\section{Maximum temperature}

In Figure 4-5 you can see that the components U (black graph) and U' (red graph) for the maximum temperature parameter are out of the critical range ( \pm 1.96$)$. According to the Mann-Kendall method, if these two components go beyond the critical range, this indicates the existence of trends in time series. The direction of the trend is also determined based on the direction of the $\mathrm{U}$ component, where $+\mathrm{U}$ indicates a positive trend in the data and $-\mathrm{U}$ indicates a negative trend in the data. Also in examining the 30-year maximum temperature of Doshan Tappeh station (1983 to 2012) based on Mann-Kendall method, we can conclude that this parameter in Doshan Tappeh station has had a positive trend in this time period. On the other hand, the collision of the two components $U$ and $U^{\prime}$ indicates that the time of the beginning of sudden change and jump in the maximum temperature of this station is after 1991. In general, the maximum temperature of this station has been increasing in recent years which will intensify after 2003.

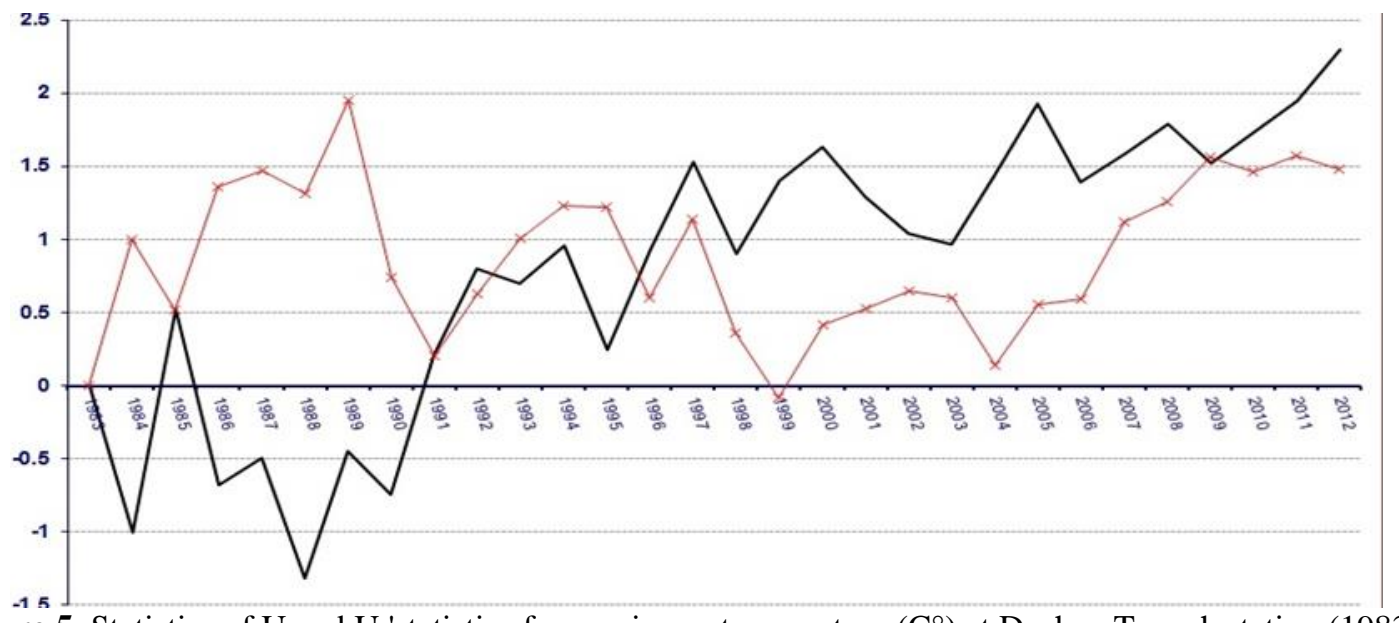

Figure 5. Statistics of $U$ and $U$ 'statistics for maximum temperature $\left(C^{\circ}\right)$ at Doshan Tappeh station (1983 to 2012)

\section{Precipitation}

In Figure 4-6 you can see that the components U (black graph) and U' (red graph) for the precipitation parameter are out of the critical range $( \pm 1.96)$. According to the Mann-Kendall method, if these two components go beyond the critical range, this indicates the existence of trends in time series. The direction of the trend is also determined based on the direction of the $\mathrm{U}$ component, where $+\mathrm{U}$ indicates a positive trend in the data and $\mathrm{U}$ indicates a negative trend in the data. Also in the study of 30 years of precipitation at Doshan Tappeh station (1983 to 2012) based on Mann-Kendall method, we can conclude that this parameter at Doshan Tappeh station had a negative trend during this period. On the other hand, the collision of the two components $U$ and $U$ 'indicates that the time of the beginning of the change in the precipitation of this station is after 1994. In general, the station's precipitation has been decreasing in recent years which will intensify after 2000. 


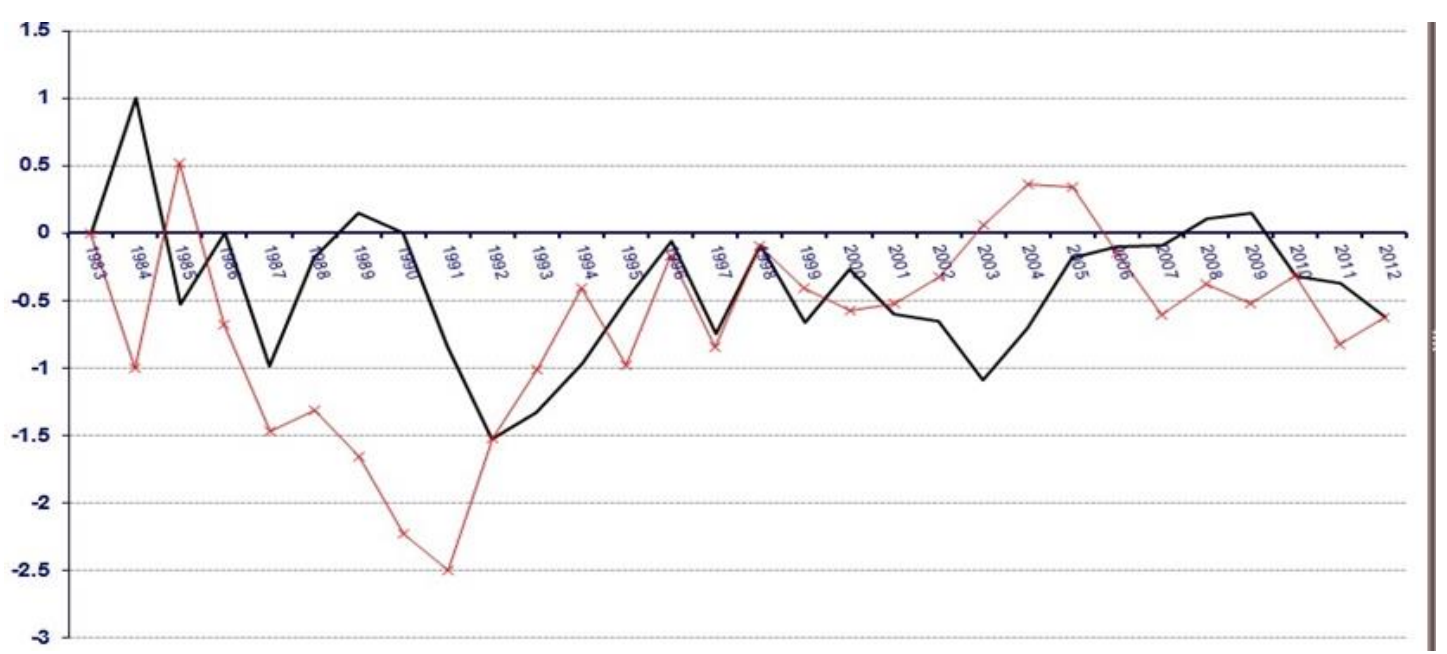

Figure 6. Statistics of U and U' Precipitation (mm) of Doshan Tappeh Station (1983-2012)

Results of temperature and precipitation forecasts for the studied stations based on SDSM model

\section{Mehrabad Station}

\section{Minimum temperature}

According to the results of the SDSM model which you can see in Figure 4-7, the trend of the minimum temperature at Mehrabad station will increase from 2015 to 2045. In other words, the minimum temperature trend of this station in the past will continue for the future (until 2045).

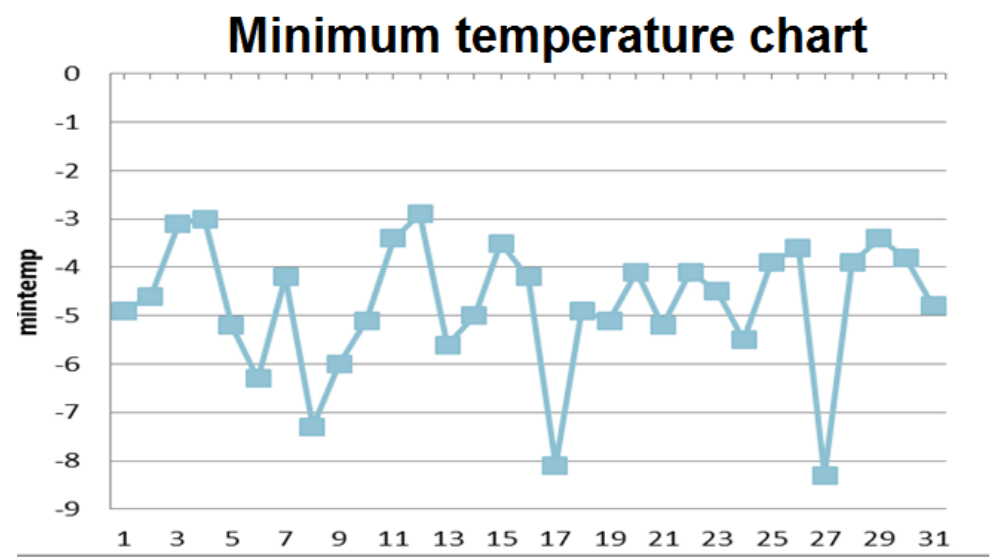

Figure 7. Minimum temperature $\left(\mathrm{C}^{\circ}\right)$ diagram in SDSM model for Mehrabad station (2014-2045)

\section{Maximum temperature}

According to the results of the SDSM model which you can see in Figure 4-8, the trend of maximum temperature at Mehrabad station will increase from 2015 to 2045. In other words, the trend of maximum temperature of this station in the past will continue for the future (until 2045). 


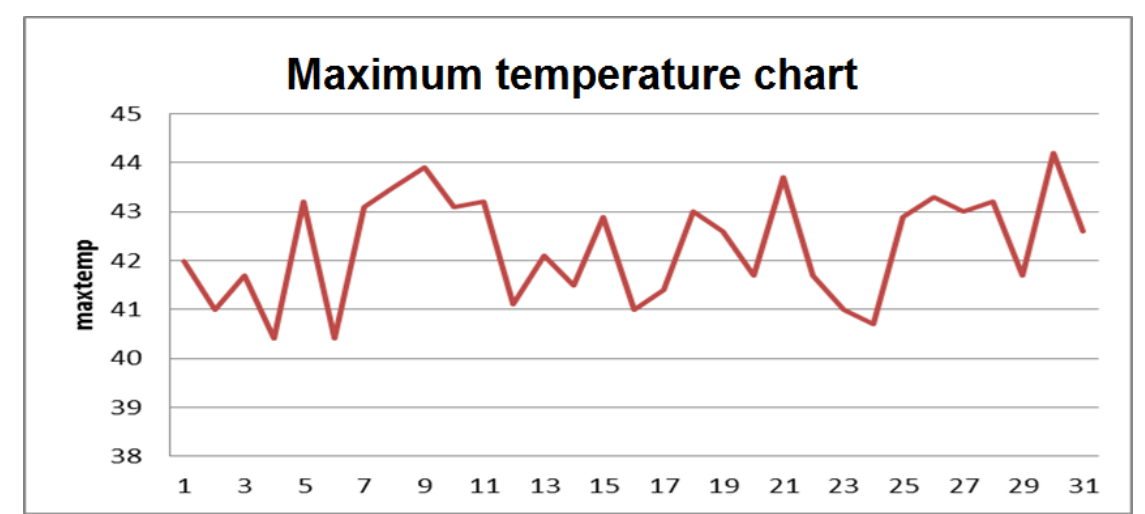

Figure 8. Diagram of maximum temperature $\left(\mathrm{C}^{\circ}\right)$ in SDSM model for Mehrabad station (2014-2045)

\section{Precipitation}

According to the results of the SDSM model which you can see in Figure 4-9, the precipitation trend at Mehrabad station will decrease from 2015 to 2045. In other words, the precipitation trend of this station in the past, will continue for the future (until 2045).

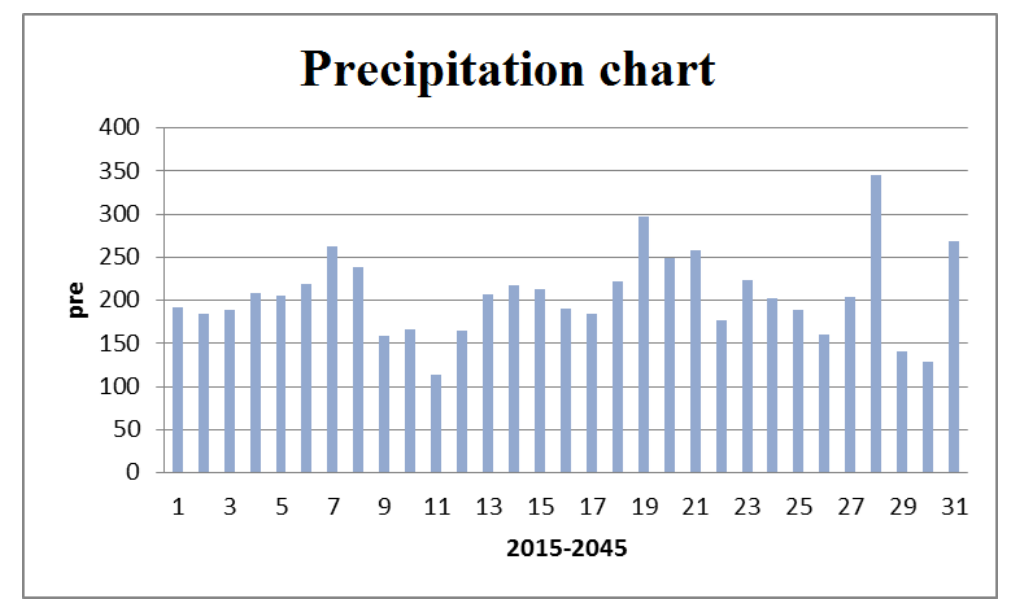

Figure 9. Precipitation diagram in SDSM model for Mehrabad station (2014-2045)

\section{Doshan TappehStation}

\section{Minimum temperature}

Based on the SDSM model results shown in Figure 4-10, the minimum temperature trend at Doshan Tappeh Station will increase from 2015 to 2045. In other words, the minimum temperature trend of this station in the past will continue for the future (until 2045).

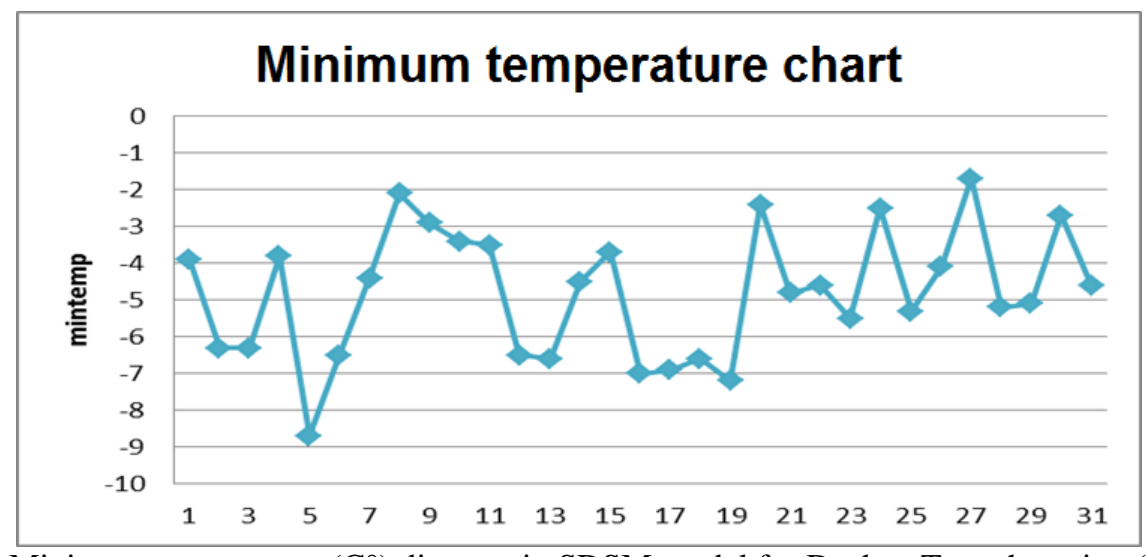

Figure 10. Minimum temperature $\left(\mathrm{C}^{\circ}\right)$ diagram in SDSM model for Doshan Tappeh station (2014-2045) 


\section{Maximum temperature}

According to the SDSM model results shown in Figure 4-11, the maximum temperature trend at Doshan Tappeh Station will increase from 2015 to 2045. In other words, the trend of maximum temperature of this station in the past will continue for the future (until 2045).

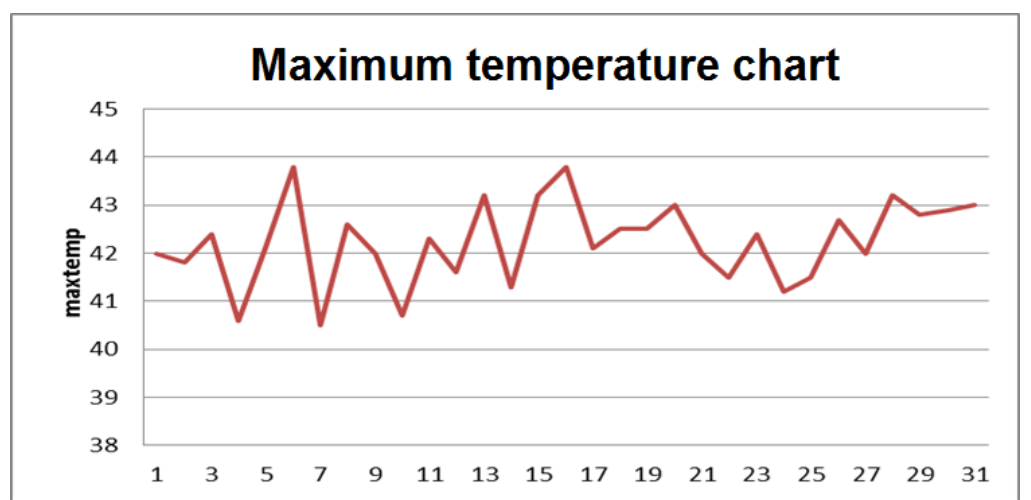

Figure 11. Maximum temperature $\left(\mathrm{C}^{\circ}\right)$ diagram in SDSM model for Doshan Tappeh station (2014-2045)

\section{Precipitation}

According to the results of the SDSM model which you can see in Figure 4-12, the precipitation trend at Doshan Tappeh station will decrease from 2015 to 2045. In other words, the precipitation trend of this station in the past, will continue for the future (until 2045).

\section{Precipitation chart}

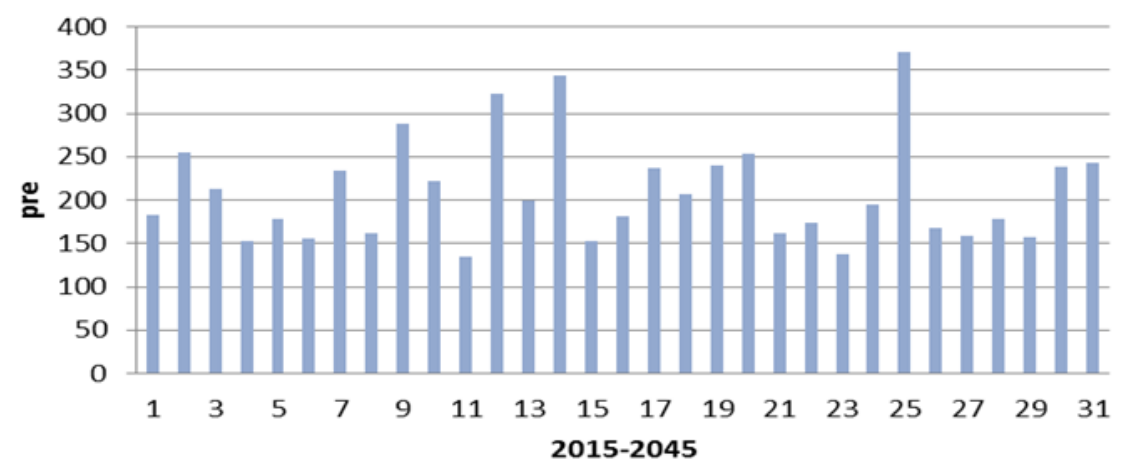

Figure 12. Precipitation(mm) diagram in SDSM model for Doshan Tappeh station (2014-2045)

\section{CONCLUSION}

Hypothesis 1: Precipitation in Tehran will decrease due to climate change.

Based on this assumption, due to the effects of climate change in Tehran at Mehrabad and Doshan Tappeh stations, the amount of precipitation will decrease in the future and as it decreased significantly before 2000, it will continue to decrease until 2045.

Hypothesis 2: The temperature of Tehran will increase due to climate change.

According to this assumption, the minimum and maximum temperatures in Tehran (which has increased significantly since 2000) will face this increasing trend until 2045. This indicates the existence of a trend of increasing the minimum and maximum temperatures of this city until 2045.

\section{REFERENCES}

American Precipitation in 1960-2000 and Links withSea Surface Temperature. Journal of Climate, 19, 14901512. 
Asadi, A., \& Heydari, A. (2011). Analysis of changes related to temperature and precipitation series in Shiraz in the period 1951 to 2005. Journal of geography and environmental planning, 22, 31(1), 152.

Asakereh, H. (2007). Climate change, Zanjan university press.

Asakereh, H. (2007). The role of humans in causing temperature changes in a recent century. Journal of geography education, 19(3).

Asakereh, H. (2012). Changing the frequency distribution in precipitation in Zanjan. Journal of geography and environmental planning, 33(1), 51-66

Azizi, G. (2004). Climate change, Qoqnoos publication.

Babaeian, I., Abassi, F., Habibi Nokhandan, M., Goli Mokhtari, L., Malbousi, S. (2010). Climate Change Assessment over Iran in the Future Decades Using MAGICC-SCENGEN Model.

Buric, D., Lukovic, J., Duvic, V., Dragojlovic, J. (2014). Recent trends in daily temperature extremes over southern Montenegro (1951-2010). Nat hazard earth syst.sci, 14, 67-72.

Chieh koa, S., \& Granguly, A.R. (2011). Intensity, duration and frequency of precipitation extremes under $21^{\text {st }}$ century warning scenarios. Journal of geophysical research, 116.

Insaf, T.Z., \& Lin, S. (2012). Climate trends in indices for temperature and precipitation across newyork state (1984-2008). Air qual atoms health, 1.

Kaviani, M.R., \& Alijani, B. (2012). Fundamentals of meteorology, Samt publications.

Kendall, M.G. (1970). Rank Correlation Methods, 2nd Ed., New York: Hafner.

Mann, H.B. (1945). Nonparametric tests against trend, Econometrica, 13, 245-259.

Meshkatee, A.H. (2015). Application of statistical models in the study of climate change and its consequences (SDSM, LARS-WG Models), Islamic Azad University press, science and research branch.

Mohammadi, H., \& Taghavi, F. (2005). The trend of temperature and precipitation limit indicators in Tehran. geographical research, 53, 151-172.

Saeidniya, A. (1989). Location of Tehran. 15(1015), 1-10.

Santos, J.L., Trebejo, I., Vincent, L.A. (2005). Trends in Total and Extreme South.

Taghavi, F., \& Mohammadi, H. (2007). A study of the return period of limit climatic events to recognize environmental consequences. ecology, 33(43), 11-20.

Zhang. Xwebin, et al. (2005). Trends in middle east climate extreme indices from 1950-2003. Journal of geographysical research, 110. 